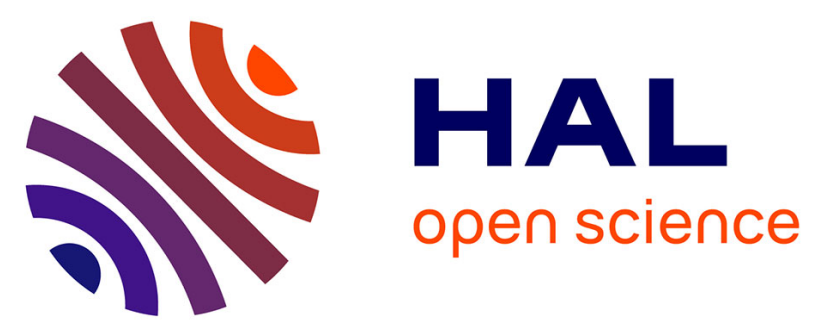

\title{
Controlled dissolution of quartz material.Part I. Controlled dissolution of quartz plates in potassium and sodium hydroxides: chemical thinning down of SC cuts
}

\author{
M. Deleuze, O. Cambon, A. Goiffon, A. Ibanez, E. Philippot
}

\section{- To cite this version:}

M. Deleuze, O. Cambon, A. Goiffon, A. Ibanez, E. Philippot. Controlled dissolution of quartz material.Part I. Controlled dissolution of quartz plates in potassium and sodium hydroxides: chemical thinning down of SC cuts. Journal de Physique IV Proceedings, 1994, 04 (C2), pp.C2-79-C2-83. 10.1051/jp4:1994210 . jpa-00252478

HAL Id: jpa-00252478 https://hal.science/jpa-00252478

Submitted on 1 Jan 1994

HAL is a multi-disciplinary open access archive for the deposit and dissemination of scientific research documents, whether they are published or not. The documents may come from teaching and research institutions in France or abroad, or from public or private research centers.
L'archive ouverte pluridisciplinaire HAL, est destinée au dépôt et à la diffusion de documents scientifiques de niveau recherche, publiés ou non, émanant des établissements d'enseignement et de recherche français ou étrangers, des laboratoires publics ou privés. 


\title{
Controlled dissolution of quartz material. Part I. Controlled dissolution of quartz plates in potassium and sodium hydroxides: chemical thinning down of SC cuts
}

\author{
M. DELEUZE, O. CAMBON* , A. GOIFFON, A. IBANEZ and E. PHILIPPOT
}

Laboratoire de Physicochimie des Matériaux Solides, UM II, URA DO407 du CNRS, C 003, Place E. Bataillon, 34095 Montpellier cedex 5, France

${ }^{*}$ C.E.P.E/Thomson, 44 Avenue de la Glacière, BP. 165, 95100 Argenteuil, France

\begin{abstract}
From previous studies suggesting that controlled crystal growth and crystal dissolution are governed by the same laws, we have previously finalized the chemical lapping or controlled dissolution of AT quartz plates in $\mathrm{NaOH}, \mathrm{H}_{2} \mathrm{O}$. The quality of chemical polishing changes with the crystallographic orientation of plates. Consequently, we have investigated similar basic solvents other than $\mathrm{NaOH}$ medium to obtain a good chemical polishing of SC cuts. Surface roughness evolution was checked and shows that controlled dissolution of SC cuts has to take place in $\mathrm{KOH}$ medium. As shown in $\mathrm{NaOH}$ medium, initial surface state has a great influence on thinning down. Dissolution rates measured against temperature in different media and activation energies are compared.
\end{abstract}

\section{I - INTRODUCTION}

Since the development of piezoelectric high frequency devices based on quartz resonators, several studies have been carried out on the frequency adjustment of this material. In the past few years, chemical polishing, opposite to Ion Beam Etching (I.B.E.), was much studied [1-6]. But, although this technics seems to be the best way to obtain a good frequency adjustment, all the last studies using $\mathrm{HF}^{2}$ and $\mathrm{NH}_{4} \mathrm{HF}_{2}$ as solvents give unsatisfactory results to their application at an industrial scale.

In our department, based on the reverse thermodynamic relations : growth and dissolution [7-12], we have finalized chemical polishing of AT quartz plates in $\mathrm{NaOH}$ medium (even after several hundreds $\mu \mathrm{m}$ of removed depth) [13]. These first results have shown that crystallographic orientations have a great influence on controlled dissolution. Thus, in $\mathrm{NaOH}$ medium, polishing of SC cuts is not satisfactory to a long removed depth (several tens $\mu \mathrm{m}$ ).

So, we have investigated other basic solvents to finalize chemical polishing of SC quartz plates. Thus, we give here the results for AT and SC cuts of quartz samples in $\mathrm{KOH}$ medium.

\section{2 - EXPERIMENTAL CONDITIONS}

Experimental conditions have been detailed previously [13-14].Therefore, only the main characteristics of chemical lapping conditions are mentioned here.

The samples used are ground or polished discs of 5 to $8 \mathrm{~mm}$ diameter and about $800 \mu \mathrm{m}$ thick.

The thinning down of plate is followed by frequency measurements. Indeed, the resonance frequency is given by :

$$
\mathrm{F}(\mathrm{MHz})=\frac{\mathrm{K}\left(\mathrm{MHz} \cdot \mu \mathrm{m}^{-1}\right)}{\mathrm{e}(\mu \mathrm{m})}
$$

where $\mathrm{e}$ is the plate thickness and $\mathrm{K}$ a constant characteristic of the material and of its orientation. For AT quartz plates $\left(\theta=35^{\circ}\right) \mathrm{K}=1670 \mathrm{MHz} . \mu \mathrm{m}^{-1}$ and 1804 for $\mathrm{SC}$ cuts $\left(\theta=34^{\circ} \varphi=22^{\circ} 45^{\prime \prime}\right)$.

Dissolution baths were prepared from high purity potassium or sodium hydroxide pellets. The dissolution reactor is in PTFE to avoid chemical corrosion.

Surface state was checked by rugosity measurement $(\mathrm{Ra})$ and by light microscopy. 


\section{3 - RESULTS AND DISCUSSION}

In these studies, the solvent used generally is $\mathrm{KOH}, 0.48 \mathrm{H}_{2} \mathrm{O}$. This concentration corresponds to an eutectic between $\mathrm{KOH}, \mathrm{H}_{2} \mathrm{O}$ and $\mathrm{KOH}$ in the binary diagram. At this composition the melting point is $99^{\circ} \mathrm{C}$, whereas $\mathrm{KOH}, \mathrm{H}_{2} \mathrm{O}$, which is a congruent melting compound, melts at $145^{\circ} \mathrm{C}$.

\section{1 - Controlled dissolution of ground AT plates in $\mathrm{KOH}, 0.48 \mathrm{H}_{2} \mathrm{O}$}

We have first investigated the behaviour of ground AT quartz plates in $\mathrm{KOH}, 0.48 \mathrm{H}_{2} \mathrm{O}$ in order to compare with the $\mathrm{NaOH}$ medium.

The initial roughness value ( $\mathrm{Ra}$ ) of the plates used is in the range $0.16-0.18 \mu \mathrm{m}$.

We plotted, figure 1, the dissolution rate against the removed depth in $\mathrm{KOH}, 0.48 \mathrm{H}_{2} \mathrm{O}$ at $191.5^{\circ} \mathrm{C}$.

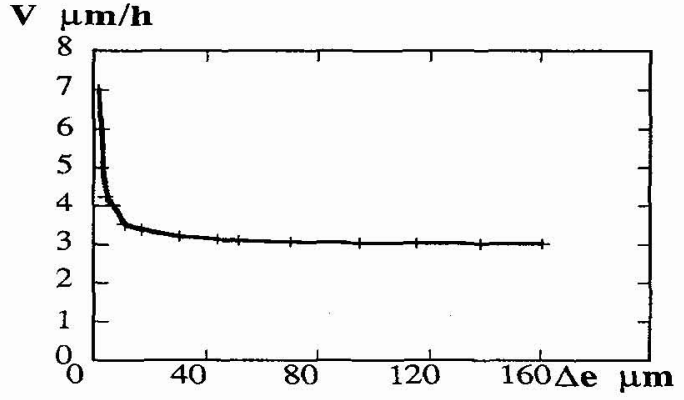

Figure 1: Dissolution rate of AT plates against removed depth in $\mathrm{KOH}, 0.48 \mathrm{H}_{2} \mathrm{O}$ at $191.5^{\circ} \mathrm{C}$.

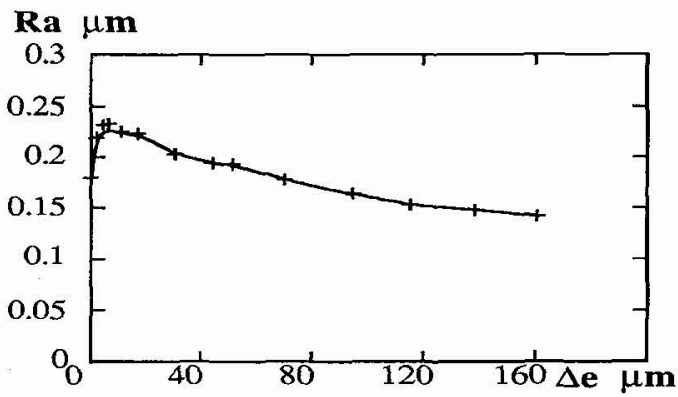

Figure 2: Ra value of AT plates against removed depth in $\mathrm{KOH}, 0.48 \mathrm{H}_{2} \mathrm{O}$ at $191.5^{\circ} \mathrm{C}$

The dissolution rate curve can be divided in two parts :

- the first part (rapid decrease of dissolution rate) corresponds to the dissolution of the polycrystalline surface layer, disturbed by cutting and polishing.

- the second part, where dissolution rate becomes constant, is characteristic of the intrinsic dissolution rate for a given orientation of the material at this temperature. Previous studies on quartz samples in acid and basic medium have already shown this behaviour [13-15].

Whatever the temperature was, the evolution of surface texture was checked by plotting Ra against removed depth (Figure 2) and by light microscopy (Figure 3).

In figure 2, roughness parameter shows a maximum for a removed depth of about $7 \mu \mathrm{m}$ corresponding to the thickness of the superficial disturbed layer for both sides. Such a behaviour has already been shown for AT quartz dissolution in $\mathrm{NaOH}$ medium [13-14]. However, after the maximum of $\mathrm{Ra}$ is reached, surface texture does not improve rapidly and roughness parameter decreases slowly to a value close to $0.14 \mu \mathrm{m}$, which corresponds to a poor controlled dissolution. This "high" value of Ra after $160 \mu \mathrm{m}$ removed is due to dissolution motive generated by the solvent $\mathrm{KOH}, 0.48 \mathrm{H}_{2} \mathrm{O}$.

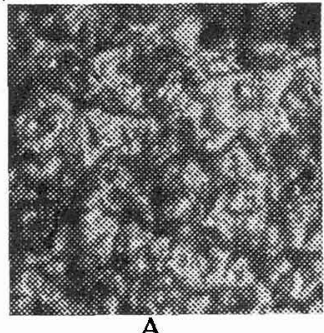

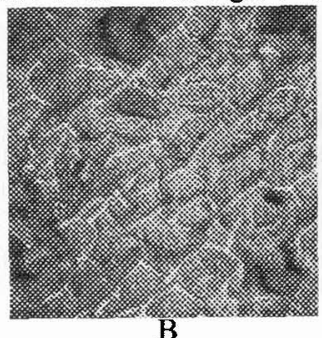

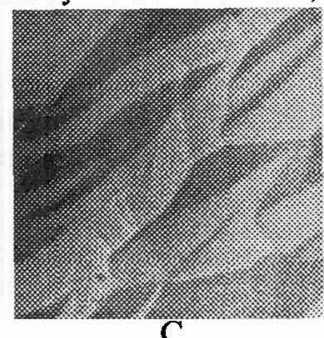

C

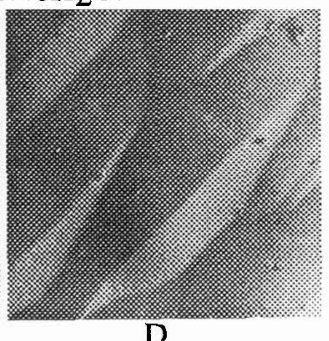

D

Figure 3: Dissolution motive of an $\mathrm{AT}$ cut in $\mathrm{KOH}, 0.48 \mathrm{H}_{2} \mathrm{O}$. A) prior to dissolution, B) $\Delta \mathrm{e}=8 \mu \mathrm{m}$,

C) $\Delta \mathrm{e}=32 \mu \mathrm{m}$, D) $\Delta \mathrm{e}=124 \mu \mathrm{m}$, Scale: $1 \mathrm{~cm}=2.3 \mu \mathrm{m}$.

Indeed, as it can be seen in figure 3 , dissolution motive is very orientated and sheer, therefore it enlarges with the dissolution depth. 
Moreover, according to the crystallographic orientation (two fold axis in the plane of cut), both sides of AT cut show identical dissolution motives and consequently the same roughness parameter.

Complementary tests at other temperatures show that, as it could be seen in previous studies [13$14]$, temperature does not influence final surface state but only the dissolution rate.

In conclusion, whereas AT cuts are well thinned down in $\mathrm{NaOH}, \mathrm{H}_{2} \mathrm{O}[13-14], \mathrm{KOH}, 0.48 \mathrm{H}_{2} \mathrm{O}$ does not allow to polish AT quartz plates .

\section{2 - Controlled dissolution of $\mathrm{SC}$ plates in $\mathrm{KOH}, \mathrm{xH}_{2} \mathrm{O}$}

As with the other solvents, this study has been carried out in two parts: surface texture and dissolution rate.

Evolutions of dissolution rates with dissolution depth are similar and can be divided in two parts as in 3.1 , only the rate value changes with temperature and solvents used, so we will present only kinetics evolution of SC cut in these solvents in 3.3 .

\section{2 .1 - Controlled dissolution of $\mathrm{SC}$ cuts in $\mathrm{KOH}, 0.48 \mathrm{H}_{2} \mathrm{O}$}

$\mathrm{SC}$ plates with different initial roughness values have been investigated. For polished $\mathrm{SC}$ cuts $(\mathrm{Ra}=$ $0,01 \mu \mathrm{m}$ ), surface texture is not affected by dissolution in $\mathrm{KOH} .0,48 \mathrm{H}_{2} \mathrm{O}$ even after several hundreds $\mu \mathrm{m}$ removed and plates present a very good $\mathrm{Ra}$ value after treatment $(\mathrm{Ra}=0,01 \mu \mathrm{m})$.

For ground SC plates, we plotted in figure 4, roughness parameter against removed depth (two types of ground SC cuts, with different initial surface states are studied).

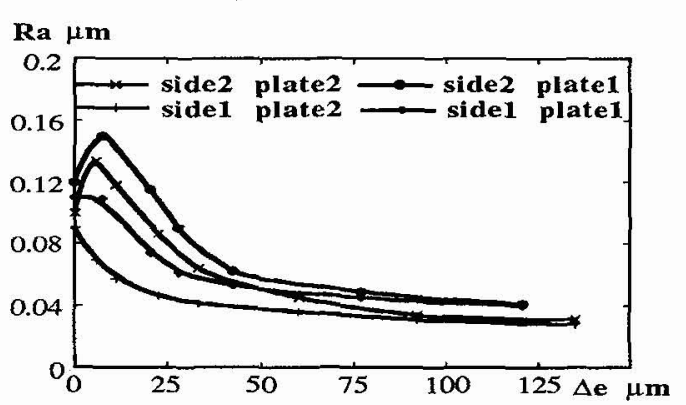

A

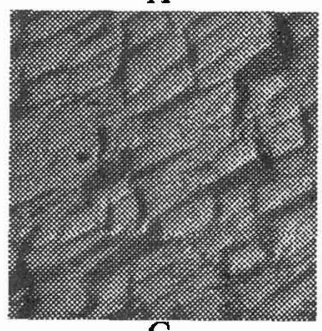

$\mathrm{C}$

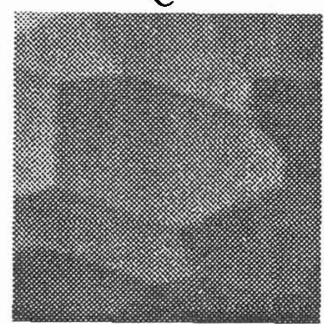

Side 1
B

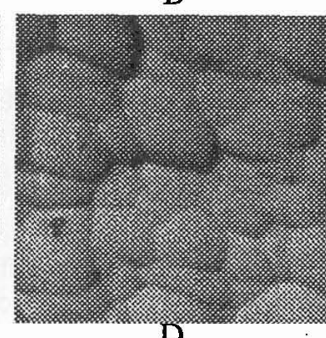

$\mathrm{D}$

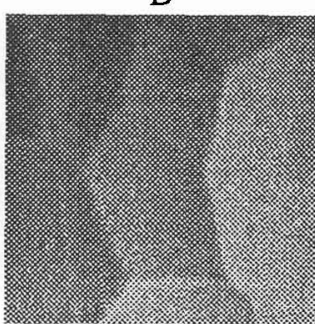

Side 2

14] [16-17], initial surface state has a great Indeed, chemical polishing is so much better as initial surface state is of good quality.

Figure 5: Dissolution motive in $\mathrm{KOH}, 0.48 \mathrm{H}_{2} \mathrm{O}$ of an SC cut . A-B) $\Delta \mathrm{e}=26 \mu \mathrm{m}, \mathrm{C}-\mathrm{D}) \Delta \mathrm{e}=118 \mu \mathrm{m}$, Scale: $1 \mathrm{~cm}=2.3 \mu \mathrm{m}$.

-The evolution of surface roughness is different for the two faces of a same SC plate. Nevertheless, after about $75 \mu \mathrm{m}$ removed, the Ra value of the two faces becomes equal.

-The final Ra value obtained corresponds to a very good surface state (ex : Plate $1: \mathrm{Ra}=0,05 \mu \mathrm{m}$ for $\Delta \mathrm{e}=75 \mu \mathrm{m}$ - Plate $2 \mathrm{Ra}=0,03 \mu \mathrm{m}$ for $\Delta \mathrm{e}=75 \mu \mathrm{m}$ ) and light microscopy of the two sides shows identical dissolution motive after several tens $\mu \mathrm{m}$ removed.

As shown in figure 5 , in the beginning of dissolution both sides have different dissolution motives whereas, after about $50 \mu \mathrm{m}$ removed, the motive of the roughest face becomes similar to the less rough face one. This phenomenon explains that $\mathrm{Ra}$ value becomes equal after several tens $\mu \mathrm{m}$ removed. 
So, $\mathrm{KOH}, 0.48 \mathrm{H}_{2} \mathrm{O}$ is a very good solvent to polish and thin down SC cuts. The roughness evolution is, as already mentionned in other medium, closely related to the initial surface state. In accordance with the crystallographic orientation, after a second rotation, the crystalline symmetry is destroyed and consequently the two sides of SC cuts show different behaviour.

\subsection{2 - Controlled dissolution of $\mathrm{SC}$ cuts in $\mathrm{KOH}, \mathrm{H}_{2} \mathrm{O}$}

As in previous studies[14](AT plates in $\mathrm{NaOH}$ medium), in order to see any effect of dilution on the evolution of surface state and on the dissolution kinetics, we have investigated a more diluted medium: $\mathrm{KOH}, \mathrm{H}_{2} \mathrm{O}$.

As in $\mathrm{KOH}, 0.48 \mathrm{H}_{2} \mathrm{O}$ medium, surface texture of polished $\mathrm{SC}$ cuts $(\mathrm{Ra}=0,01 \mu \mathrm{m})$ is not affected by dissolution process.

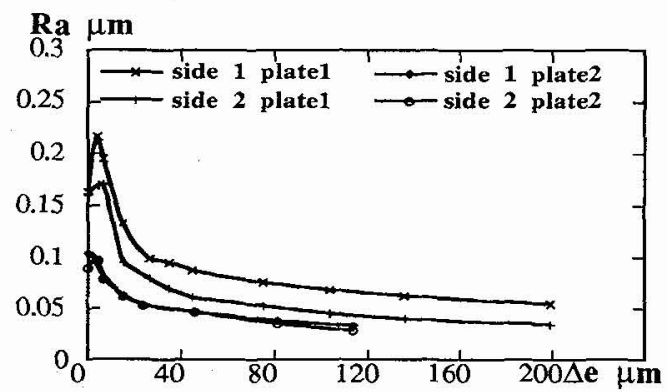

Figure 6:Roughness parameter Ra plotted against removed depth for different $\mathrm{SC}$ plates in $\mathrm{KOH}, \mathrm{H}_{2} \mathrm{O}$.
A

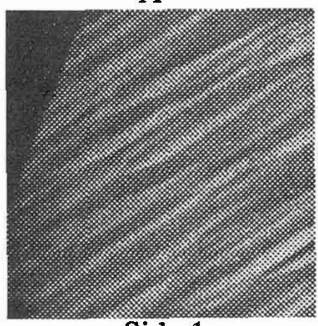

Side 1
B

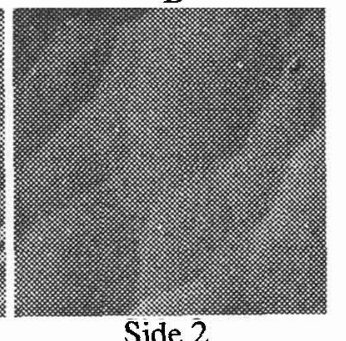

Side 2

Figure 7: Dissolution motive of an SC cut in $\mathrm{KOH}, \mathrm{H}_{2} \mathrm{O}$. A-B) $\Delta \mathrm{e}=79 \mu \mathrm{m}$, Scale: $1 \mathrm{~cm}=2.3$ $\mu \mathrm{m}$.

For ground samples, evolution of Ra value against dissolution depth is plotted in figure 6 . Two types of samples with different initial surface states were investigated. As shown in 3.2.1, initial surface state has a great influence on controlled dissolution. However, in this medium, evolution of surface roughness of the two sides of plates is different. Indeed, light microscopy of dissolution motive of the two faces (figure 7) shows that in $\mathrm{KOH}, \mathrm{H}_{2} \mathrm{O}$, dissolution motives are different (for all the plates). One face presents an alveolate relief ( $R$ a minimum) whereas the second face presents a striated relief (Ra maximum) which corresponds to an elongated alveolate relief.

Furthermore, in the opposite of plate 2, Ra value evolution of both sides of plate 1 are different. Differences observed can be attributed to the small height of striated relief face, in the beginning of dissolution when initial surface state is good. In this case, both motives present same Ra values.

Nevertheless, a good $\mathrm{Ra}$ value is obtained in this medium $(\sim 0,06 \mu \mathrm{m}$ for plate 1 after $120 \mu \mathrm{m}$ removed). The low value of $\mathrm{Ra}(0,05 \mu \mathrm{m})$ after $40 \mu \mathrm{m}$ removed for plate 2 is only due to the good initial surface state.

In conclusion, $\mathrm{KOH}, \mathrm{H}_{2} \mathrm{O}$ is a solvent as good as $\mathrm{KOH}, 0.48 \mathrm{H}_{2} \mathrm{O}$ for $\mathrm{SC}$ cuts (cf 3.2.1). But, for the common used plates ( $\mathrm{Rai} \approx 0.12 \mu \mathrm{m}$ ) $\mathrm{KOH}, 0.48 \mathrm{H}_{2} \mathrm{O}$ is better because the Ra value of the two sides becomes adjoining more rapidly.

\section{3 - Dissolution kinetics in $\mathrm{KOH}_{,} \mathrm{xH}_{2} \mathrm{O}$ medium}

We have plotted in figure 8 the evolution of dissolution rate against temperature. For comparison, kinetic dissolution of AT cut in $\mathrm{NaOH}, \mathrm{H}_{2} \mathrm{O}$ medium [13-14] is plotted too. Dissolution rate is strongly influenced by temperature. As it could be seen in previous studies [13-14], exponential variation corresponds to a thermally activated mechanism, following Arrhenius' law : $\mathrm{K}_{\mathrm{T}}=\mathrm{A} \cdot \exp (-\mathrm{Ea} / \mathrm{RT})$. Plotting $\ln \mathrm{V}=\mathrm{f}(1 / \mathrm{T})$, we can calculate activation energies in $\mathrm{Kj}_{\mathrm{j}} \mathrm{mole}^{-1}$ ( Table 1 ). 


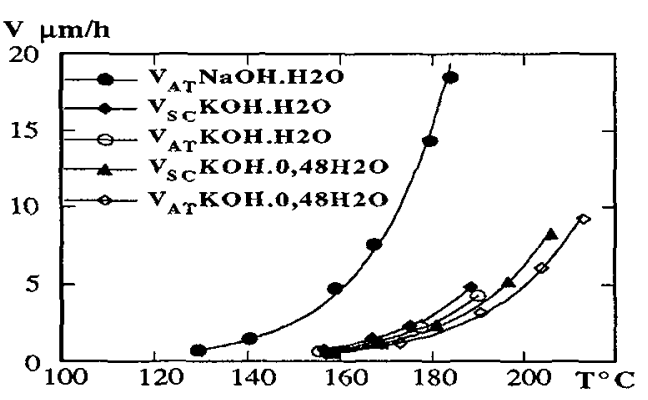

Figure 8: Dissolution rate of AT and SC plates in basic media against temperature.

Furthermore, the activation energies are the same $(\Delta \mathrm{Ea}=6 \%)$ and thus, the same chemical dissolution process would have to take place.

In conclusion, $\mathrm{KOH}, 0.48 \mathrm{H}_{2} \mathrm{O}$ seems to be the best solvent for $\mathrm{SC}$ cut in terms of dissolution rate because $\mathrm{KOH}, \mathrm{H}_{2} \mathrm{O}$ cannot be used at higher temperatures than $190^{\circ} \mathrm{C}$ which corresponds to its boiling point.

\section{4 - CONCLUSION}

We can conclude from these results that the best conditions for controlled dissolution of SC quartz plates is the use of $\mathrm{KOH}, 0.48 \mathrm{H}_{2} \mathrm{O}$ medium. The good results obtained allow to envisage, as for the AT cuts in $\mathrm{NaOH}, \mathrm{H}_{2} \mathrm{O}$ medium, an industrialisation of this process.

Therefore, our previous studies [13-14] and these results show that, in a same basic medium, dissolution process is largely affected by the crystallographic orientation of plates and the samples preparation. Indeed, a great difference is observed between the thinning down of AT and SC cuts in $\mathrm{KOH}, 0.48 \mathrm{H}_{2} \mathrm{O}$. Dissolution motive and consequently evolution of surface state, both generated by dissolution process, are different for the two cuts. Futhermore, dissolution rate changes with orientation although activation energies are the same. This fact shows that chemical dissolution mechanism must be the same but small differences of dissolution rates are due to the different atomic structure in surface plane.

Nevertheless, the solvent has a great influence on dissolution process for a same orientation. So, the best solvent for a good thinning down differs with plate orientation: $\mathrm{NaOH}, \mathrm{H}_{2} \mathrm{O}$ for AT cuts and $\mathrm{KOH}, 0.48 \mathrm{H}_{2} \mathrm{O}$ for $\mathrm{SC}$ cuts.

In order to find a single solvent for different orientations, further works are in progress to explain on one hand, evolution of dissolution rate and on the other hand, the mechanism of dissolution and in particular the role of cations and the influence of superficial atomic structure.

Acknowledgements: The authors wish to thank CNRS and C.E.P.E/Thomson for their financial support .

\section{References:}

[1] : K.Bräuer, E.Müller, Crystal Res \& Technol ( 1984) 101.

[2] : K.H.Jones, 41st Annual Frequency Control Symposium ( 1987 ) 199.

[3] : C.R.Tellier, Surface Technology ( 1984 ) 21, 83.

[4] : A.J.Bernot, IEEE ( 1985 ) 271.

[5] : R.J Brandmayr, J.R.Vig, 39th Annual Frequency Control Symposium ( 1985 ) 273.

[6] : R.J Brandmayr, J.R.Vig, 40th Annual Frequency Control Symposium ( 1985 ) 86.

[7] : J Frenkel, J.Phys.USSR 9 ( 1945 ) 392.

[8] : W.K.Burton, N.Cabrera, F.Frank, Nature C ( 1949 ) 163, 398.

[9] : W.K.Burton, N.Cabrera, F.Frank, Phil.Trans.Soc.London C ( 1951 ) 243, 299.

[10] : P.Bennena, G.H.Gilmer, J.Cryst.Growth, 13 ( 1972 ) 148.

[11] : W.G.Johnston, Prog.Ceram.Sci, 2 ( 1962 ) 1.

[12] : N.Cabrera, N.Levine, Phil.Mag, 1 ( 1955 ) 450.

[13] : M.Deleuze, O.Cambon, A.Goiffon, I.Ibanez, E.Philippot, IEEE I.F.C.S, June 2-4 ( 1993 ) 381.

[14] : M.Deleuze, O.Cambon, A.Goiffon, I.Ibanez, E.Philippot, J.Mater.Sci ( to be published ).

[15] : C.R.Tellier, J.L.Vaterkowski, 1985 ,Surface Technology, 15; 275.

[16] : C.R. Tellier, J.L. Waterkowski, Surf. Technol. 15 ( 1985 ) 275.

[17] : Y. Sekiguchi, H. Funakubo, J. Mater. Sci. 15 ( 1980$) 3066$. 